\title{
Effect of Uniform Magnetic Field on Melting at Various Rayleigh Numbers
}

\author{
Sumer Bharat Dirbude ${ }^{a^{*}}$, Vivek Kumar Maurya ${ }^{b}$ \\ ${ }^{a}$ Assistant Professor, National Institute of Technology Delhi, Delhi-40, India \\ ${ }^{b}$ M. Tech. Student, National Institute of Technology Delhi, Delhi-40, India
}

\begin{abstract}
Melting phenomena occurs in various industrial applications, such as metal castings of turbine blades, environmental engineering, PCM-based thermal storage devices, etc. During the design of these devices, they are designed for efficient heat transfer rate. To improve the heat transfer rate, understanding of the important flow processes during the melting (and solidification) is necessary. An objective of the present work is to study the effect of natural convection and magnetic field on interface morphology and thereby on melting rate. In this work, therefore, an effect of uniform transverse magnetic field on the melting inside a cavity, filled initially with solid gallium, at various Rayleigh numbers $\left(\mathrm{Ra}=3 \times 10^{5}, 6 \times 10^{5}\right.$, and $\left.9 \times 10^{5}\right)$ is presented. A $2 \mathrm{D}$ unsteady numerical simulation, with the enthalpy-porosity formulation, is performed using ANSYS-Fluent. The magnetic field is characterized by the Hartmann number (Ha) and the results are shown for the $\mathrm{Ha}=0,30$ and 50 . The horizontal walls of the cavity are considered insulated and vertical walls are respectively considered hot and cold. It is observed that the role of natural convection during the melting is significant on the temperature distribution and solid-liquid interface. The increased magnetic field ( $\mathrm{Ha}=30$ and 50) found to have a suppressing effect on the dominance of natural convection at all Rayleigh numbers $\left(\mathrm{Ra}=3 \times 10^{5}, 6 \times 10^{5}\right.$, and $\left.9 \times 10^{5}\right)$.
\end{abstract}

\section{Keywords:}

Magneto-hydrodynamics; Melting and Solidification; CFD Simulations;

Natural Convection; The Hartmann Number.

\section{Article History:}

Received: 14 May 2019 Accepted: 19 July 2019

\section{1- Introduction}

Melting occurs in metal castings of turbine blades, environmental engineering, PCM-based thermal storage devices, nuclear reactor systems, materials processing, solar energy systems, etc. [1]. To improve the melting rate and heat transfer efficiency, understanding of the important flow processes is necessary. The natural convection, for example, can affect the liquid-solid interface morphology. If the liquid is electrically conducting then the interface morphology also depend on the interaction of the buoyancy force and Lorentz force. Thus, the imposed magnetic field can control the melting rate in the electrically conducting fluid. Hence, there is considerable interest in studying the physics that affect the rate of melting (or solidification) preferably inside a rectangular enclosure.

The effect of natural convection on the solid-interface morphology during the melting of gallium has been experimentally studied by Gau and Viskanta (1986) and Dadzis et al. (2016) [2,3]. They considered a classical differentially heated rectangular cavity and observed a strong effect of natural convection on the interface and the heat transfer rate. Numerical work has been conducted, for instance, by Dadzis et al. (2016), Brent et al. (1988), Bertrand et al. (1999) and Farsani et al. (2017) [3-6]. Also confirmed a strong effect of natural convection on the interface and the heat transfer rate. Various geometry configurations and various boundaries and initial conditions have been studied, for instance, by Rady and Mohanty (1996), Bucchignani (2009), Joulin et al. (2009) and Ben-David et al. (2016) [7-10], to study the effect of natural convection.

\footnotetext{
*CONTACT: Sumery7@gmail.com; Sbdirbude@gmail.com

DOI: http://dx.doi.org/10.28991/esj-2019-01189
}

(C) 2019 by the authors. Licensee ESJ, Italy. This is an open access article under the terms and conditions of the Creative Commons Attribution (CC-BY) license (https://creativecommons.org/licenses/by/4.0/). 
The effect of magnetic field on the solid-interface morphology during the melting of gallium inside a rectangular enclosure is studied, for instance, by Farsani et al. (2017), Kang et al. (2013), Bondareva et al. (2016), Juel et al. (1999), $\mathrm{Xu}$ et al. (2006), Sathiyamoorthy and Chamkha (2012), Ghalambaz et al. (2017), Avnaim et al. (2018) and Avnaim et al. (2018) [6, 11-18]. The study of convection has not been limited to the external static magnetic field only, but also electric and electromagnetic field [19] and traveling magnetic field [3, 10, 17, 18, 20] have been studied. From the above literature, it is interesting to note that the effect of a longitudinal or transverse magnetic field substantially affect the heat and fluid-flow structures.

In the modeling of magneto-hydrodynamic flows, it is important to consider the effect of three-dimensionality and in the homogeneity of the strong magnetic field. Despite the limitation offered in the physical significance, two-dimensional modeling of the flows is often considered as it offers simplification and possibility of analyses over a wide range of nondimensional parameters in lesser time. In this work, a 2D unsteady numerical simulation, using ANSYS-Fluent with the enthalpy-porosity formulation, are performed to study an effect of a uniform horizontal magnetic field on melting inside a cavity filled initially with solid gallium at various Rayleigh numbers $\left(\mathrm{Ra}=3 \times 10^{5}, 6 \times 10^{5}\right.$, and $\left.9 \times 10^{5}\right)$. By varying the Rayleigh numbers, the buoyancy force is varied. The horizontal walls of the cavity are considered insulated and vertical walls are, respectively, considered hot and cold. The magnetic field and the resulting Lorentz force are characterized by the Hartmann number ( $\mathrm{Ha}$ ) and the results are shown for the $\mathrm{Ha}=0,30$ and 50.

\section{2- Numerical Methodology}

Figure 1 shows the classical rectangular cavity geometry with boundary conditions. The left and right walls are maintained at a uniform isothermal temperature of $\mathrm{T}_{\mathrm{h}}=311.15 \mathrm{~K}$ and $\mathrm{T}_{\mathrm{c}}=301.15 \mathrm{~K}$, respectively. A horizontal uniform magnetic field, as shown in the figure, is imposed in the horizontal direction, i.e. perpendicular to hot and cold walls. The aspect ratio of the cavity is 1.0 and the cavity is filled with the pure solid gallium. The initial temperature of the cavity is $302.85 \mathrm{~K}$ i.e. less than the melting point of gallium. The flow properties, except density, are assumed to be constants, as the maximum temperature difference (i.e., 10) is very small. To perform 2-D unsteady, laminar flow numerical simulations, following governing equations with enthalpy-porosity formulation are solved. The governing equations are:

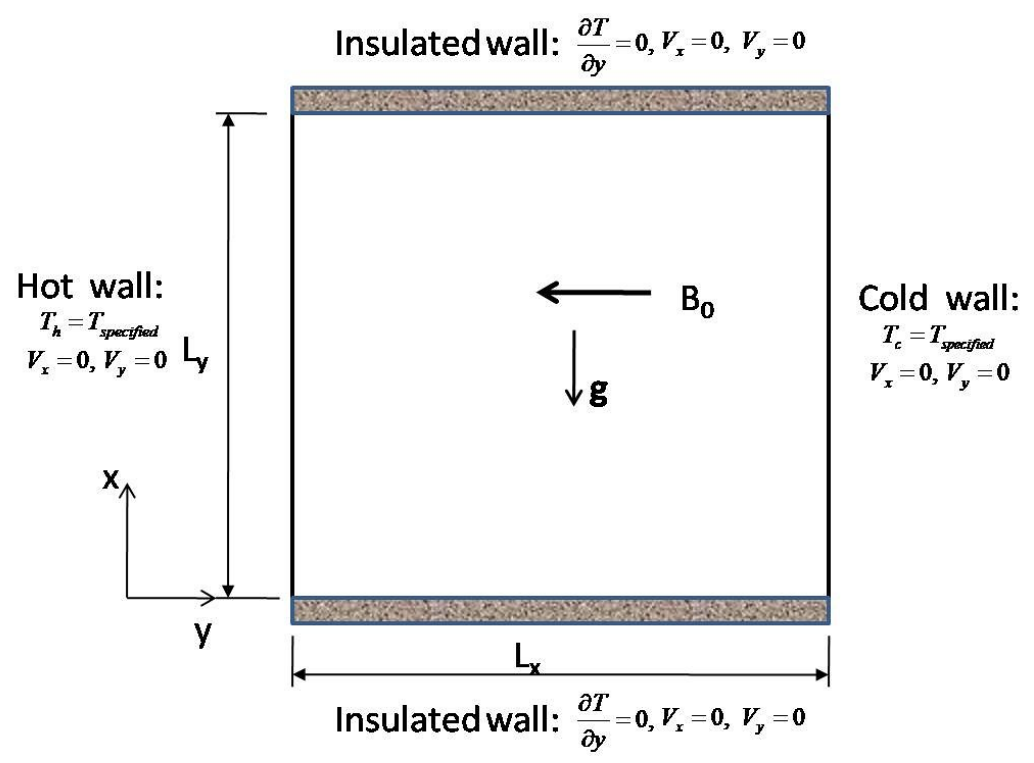

Figure 1. Problem geometry with boundary conditions.

1. Continuity equation: $\frac{\partial \mathrm{v}_{\mathrm{x}}}{\partial \mathrm{x}}+\frac{\partial \mathrm{V}_{\mathrm{y}}}{\partial \mathrm{y}}=0$

2. Momentum in $\mathrm{x}$-direction:

$\frac{\partial \mathrm{V}_{\mathrm{x}}}{\partial \mathrm{t}}+\mathrm{V}_{\mathrm{x}} \frac{\partial \mathrm{V}_{\mathrm{x}}}{\partial \mathrm{x}}+\mathrm{V}_{\mathrm{y}} \frac{\partial \mathrm{V}_{\mathrm{x}}}{\partial \mathrm{y}}=-\frac{1}{\rho} \frac{\partial \mathrm{P}}{\partial \mathrm{x}}+\mathrm{v}\left(\frac{\partial^{2} \mathrm{~V}_{\mathrm{x}}}{\partial \mathrm{x}^{2}}+\frac{\partial^{2} \mathrm{~V}_{\mathrm{x}}}{\partial \mathrm{y}^{2}}\right)+\mathrm{I}(\mathrm{T}) \mathrm{V}_{\mathrm{x}}$

Momentum in y-direction:

$\frac{\partial \mathrm{V}_{\mathrm{y}}}{\partial \mathrm{t}}+\mathrm{V}_{\mathrm{x}} \frac{\partial \mathrm{V}_{\mathrm{y}}}{\partial \mathrm{x}}+\mathrm{V}_{\mathrm{y}} \frac{\partial \mathrm{V}_{\mathrm{y}}}{\partial \mathrm{y}}=-\frac{1}{\rho} \frac{\partial \mathrm{P}}{\partial \mathrm{y}}+\mathrm{g} \beta\left(\mathrm{T}-\mathrm{T}_{\mathrm{ref}}\right)-\left(\sigma \mathrm{B}_{0}^{2}\right) \mathrm{V}_{\mathrm{y}}+\mathrm{v}\left(\frac{\partial^{2} \mathrm{~V}_{\mathrm{y}}}{\partial \mathrm{x}^{2}}+\frac{\partial^{2} \mathrm{~V}_{\mathrm{y}}}{\partial \mathrm{y}^{2}}\right)+\mathrm{I}(\mathrm{T}) \mathrm{V}_{\mathrm{y}}$

Where $\mathrm{I}(\mathrm{T})=\mathrm{K}_{\text {mush }}(1-\gamma)^{2} /\left(\gamma^{3}+\epsilon\right), \mathrm{K}_{\text {mush }}=10^{5}, \in$ is a small number $(0.001), \rho=\rho_{\text {ref }}\left[1-\beta\left(\mathrm{T}-\mathrm{T}_{\text {ref }}\right)\right]$, liquid fraction $\gamma=0$, if $\mathrm{T}<\mathrm{T}_{\text {solidus }}, \gamma=1$, if $\mathrm{T}>\mathrm{T}_{\text {liquidus }}$ and $\gamma=\left(\mathrm{T}-\mathrm{T}_{\text {solidus }}\right) /\left(\mathrm{T}_{\text {liquidus }}-\mathrm{T}_{\text {solidus }}\right)$. 
3. Energy equations: $\frac{\partial \mathrm{H}}{\partial \mathrm{t}}+\mathrm{V}_{\mathrm{x}} \frac{\partial \mathrm{H}}{\partial \mathrm{x}}+\mathrm{V}_{\mathrm{y}} \frac{\partial \mathrm{H}}{\partial \mathrm{y}}=\frac{\mathrm{k}}{\rho C_{\mathrm{p}}}\left(\frac{\partial^{2} \mathrm{H}}{\partial \mathrm{x}^{2}}+\frac{\partial^{2} \mathrm{H}}{\partial \mathrm{y}^{2}}\right)$

Where $\mathrm{H}=\mathrm{h}+\Delta \mathrm{H}$, and $\mathrm{h}=\mathrm{h}_{\text {ref }}+\int_{\mathrm{T}_{\mathrm{ref}}}^{\mathrm{T}} \mathrm{C}_{\mathrm{P}} \mathrm{T}$.

Table 1. Thermo-physical properties of pure gallium [2, 16].

\begin{tabular}{cccc}
\hline Property & Value & Property & Value \\
\hline Prandtl number $(\mathrm{Pr})$ & 0.0216 & Fluid dynamic viscosity $(\mu)$ & $0.00181 \mathrm{~kg} / \mathrm{ms}$ \\
Stefan number (Ste) & 0.039 & Fluid kinematic viscosity $(v)$ & $11.375 \times 10^{-7} \mathrm{~m}^{2} / \mathrm{s}$ \\
Rayleigh number $(\mathrm{Ra})$ & $3 \times 10^{5}, 6 \times 10^{5}$, and $9 \times 10^{5}$ & Thermal diffusivity $(\alpha)$ & $1.375 \times 10^{-5} \mathrm{~m}^{2} / \mathrm{s}$ \\
Density $(\rho)$ & $6322-0.678 \mathrm{~T} \mathrm{~kg} / \mathrm{m}^{3}$ & Electrical conductivity $(\sigma)$ & $7.1 \times 10^{6} \mathrm{~S} / \mathrm{m}$ \\
Thermal conductivity $(\mathrm{k})$ & $32 \mathrm{~W} / \mathrm{mK}$ & Magnetic permeability of free space $\left(\mu_{0}\right)$ & $1.257 \times 10^{-6}$ \\
Latent heat of fusion $\left(\mathrm{h}_{\mathrm{f}}\right)$ & $80160 \mathrm{~J} / \mathrm{kg}$ & Solidus temperature & $302.85 \mathrm{~K}$ \\
Specific heat $(\mathrm{Cp})$ & $381.5 \mathrm{~J} / \mathrm{kg} \mathrm{K}$ & Liquidus temperature & $302.85 \mathrm{~K}$ \\
Thermal expansion coefficient $(\beta)$ & $1.2 \times 10^{-4}(1 / \mathrm{K})$ & Acceleration due to gravity $(\mathrm{g})$ & $9.81 \mathrm{~m} / \mathrm{s}^{2}$
\end{tabular}

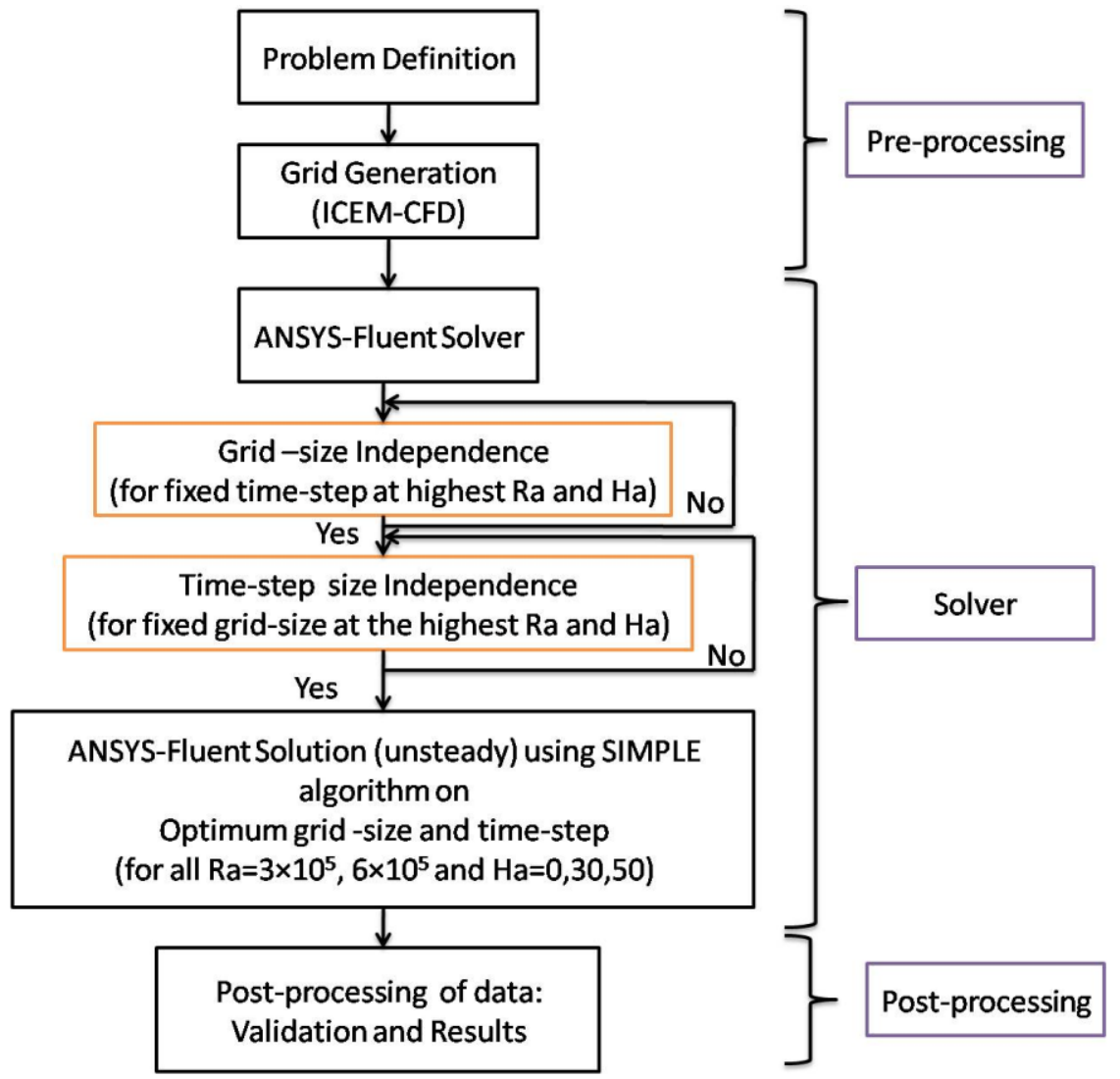

Figure 2. Flow-chart showing solution methodology.

In the current problem gravity force along with Lorentz force (due to the external magnetic field) is considered. Uniform magnetic field with varying strength (as characterized by the Hartmann number) has been applied normal to the right wall as shown in the figure. The electrically conducting gallium interacts with an external horizontal uniform magnetic field of constant magnitude, $B_{0}$. The magnetic field produced by the movement of liquid gallium has been assumed to be negligible as compared to externally applied magnetic field (low magnetic Reynolds number approximation) and cavity walls are electrically insulating. With this approximation, electromagnetic force reduces to $\left(\sigma \mathrm{B}_{0}{ }^{2}\right) \mathrm{V}_{\mathrm{y}}$ only, as shown in Eq. (3). The dimensionless parameters considered to characterize flow-problem are: the Rayleigh number, $\mathrm{R}_{\mathrm{a}}=\left(\rho^{2} \mathrm{C}_{\mathrm{p}} \mathrm{g} \beta\left(\mathrm{T}_{\mathrm{h}}-\mathrm{T}_{\mathrm{c}}\right) \mathrm{L}_{\mathrm{y}}^{3}\right) /(\mu \mathrm{k})$; the Stefan number, $\mathrm{St}_{\mathrm{e}}=\left(\mathrm{C}_{\mathrm{p}}\left(\mathrm{T}_{\mathrm{h}}-\mathrm{T}_{\mathrm{c}}\right)\right) /\left(\mathrm{h}_{\mathrm{f}}\right)$; the Prandtl number, $\mathrm{P}_{\mathrm{r}}=\left(\mu \mathrm{C}_{\mathrm{p}}\right) /(\mathrm{k})$; the Hartmann number: $\mathrm{Ha}=\mathrm{B}_{0} \mathrm{~L}_{\mathrm{y}} \sqrt{\sigma / \rho v v}$, the Fourier number, Fo $=\alpha \mathrm{t} / \mathrm{L}_{\mathrm{y}}^{2}$ where $\mathrm{t}$ is time, a dimensionless time, $\tau=\mathrm{St}_{\mathrm{e}} \times \mathrm{Fo}$, the averaged Nusselt number, $(\mathrm{Nu})_{\text {avg }}=\left(\mathrm{q}^{\prime} \cdot \Delta \mathrm{Y}\right) /(\Delta \mathrm{T} \cdot \mathrm{k})$ where $\mathrm{q}^{\prime}$ is the heat flux, $\Delta \mathrm{Y}$ is the change in length at the point of estimation and $\Delta \mathrm{T}$ is the temperature change with the reference temperature and $\mathrm{k}$ is the thermal conductivity of fluid. In the non-dimensional parameters, $\mathrm{g}$ is the acceleration due to 
gravity, $C_{p}$ is the specific heat, $\beta$ is the coefficient of thermal expansion, $L_{y}$ is the length of the side of the square cavity, $v$ is the kinematic viscosity, $\alpha$ is the thermal diffusivity, $\sigma$ is the electrical conductivity, and $\rho$ is the density.

To solve the governing equations, the SIMPLE method and the second-order accurate scheme in discretizing the momentum and energy conservation equations is used. The pressure is solved using PRESTO!. The stopping criterion for the solution of energy, momentum and continuity, is $10^{-6}, 10^{-4}$ and $10^{-4}$, respectively. Simulations are performed on Rayleigh numbers $\left(\mathrm{Ra}=3 \times 10^{5}, 6 \times 10^{5}\right.$, and $\left.9 \times 10^{5}\right)$. At fixed $\mathrm{Ra}$, the Hartmann number $(\mathrm{Ha})$ is varied from 0,30 and 50. The thermo-physical properties of pure gallium considered in the present simulation are mentioned in Table 1 . The above discussed methodology is shown in the form of the flowchart in Figure 2.

\section{3- Results and Discussions}

To perform the numerical simulation, it is important to perform grid-size independence, time-step size independence and validation and verification of the model. Therefore, grid-size independence, time-step size independence and validation and verification are shown first with results at Rayleigh numbers $\left(\mathrm{Ra}=3 \times 10^{5}, 6 \times 10^{5}\right.$, and $\left.9 \times 10^{5}\right)$ and the Hartmann number $(\mathrm{Ha}=0,30$ and 50) next, followed by the average Nusselt number on the hot wall.

\section{3-1- Grid-size Independence, Time-step Independence and Validation}

Figure 3 shows the time-step independence at $\mathrm{dt}=1.0,0.1,0.01$ and grid-size independence at mesh-1 (75 $\times 75$ cells),

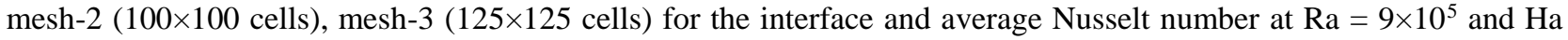
$=50$. It is observed from the figure that the time-step $=0.1$ and mesh-2 $(100 \times 100)$ found optimum for further calculations.
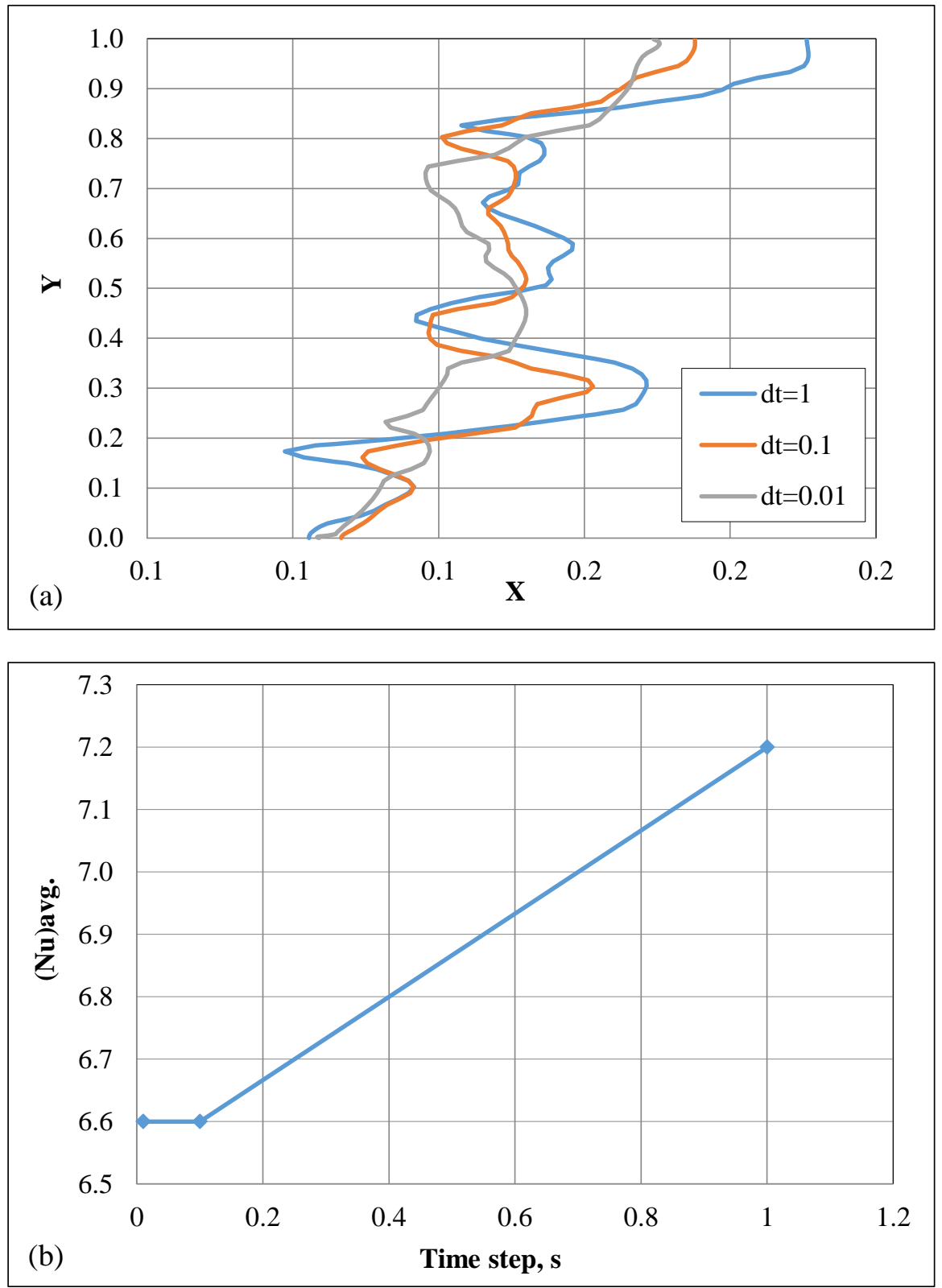

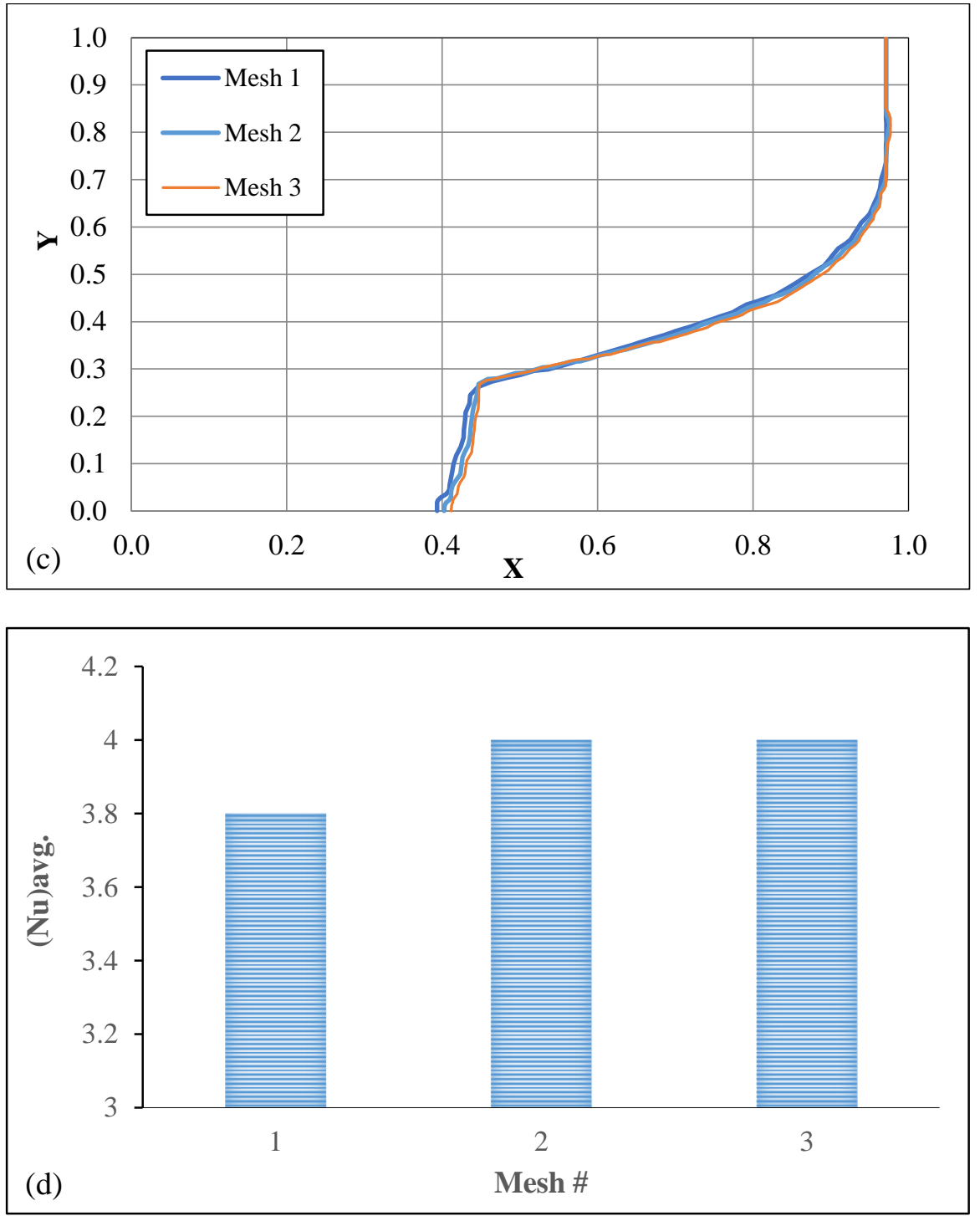

Figure 3. Time-step (dt) independence: (a) Interface; (b) Average Nusselt number; Grid-size independence: (c) Interface; (d) Average Nusselt number.

Figure 4 shows the comparison of the present calculations with the numerical data of [21] at $\mathrm{Ha}=0$ and various $\tau$ 's and $\mathrm{Ha}=0,30,50$ and fixed $\tau$. The Figure shows a reasonable qualitative match with the numerical data with a difference of less than $10 \%$.

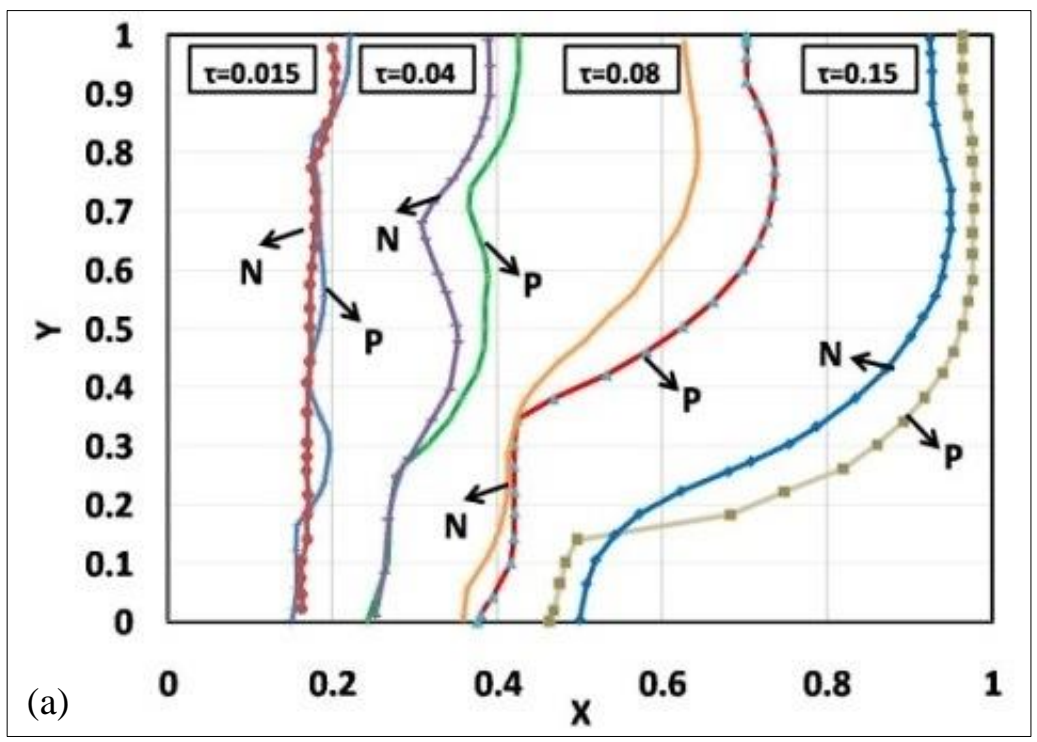




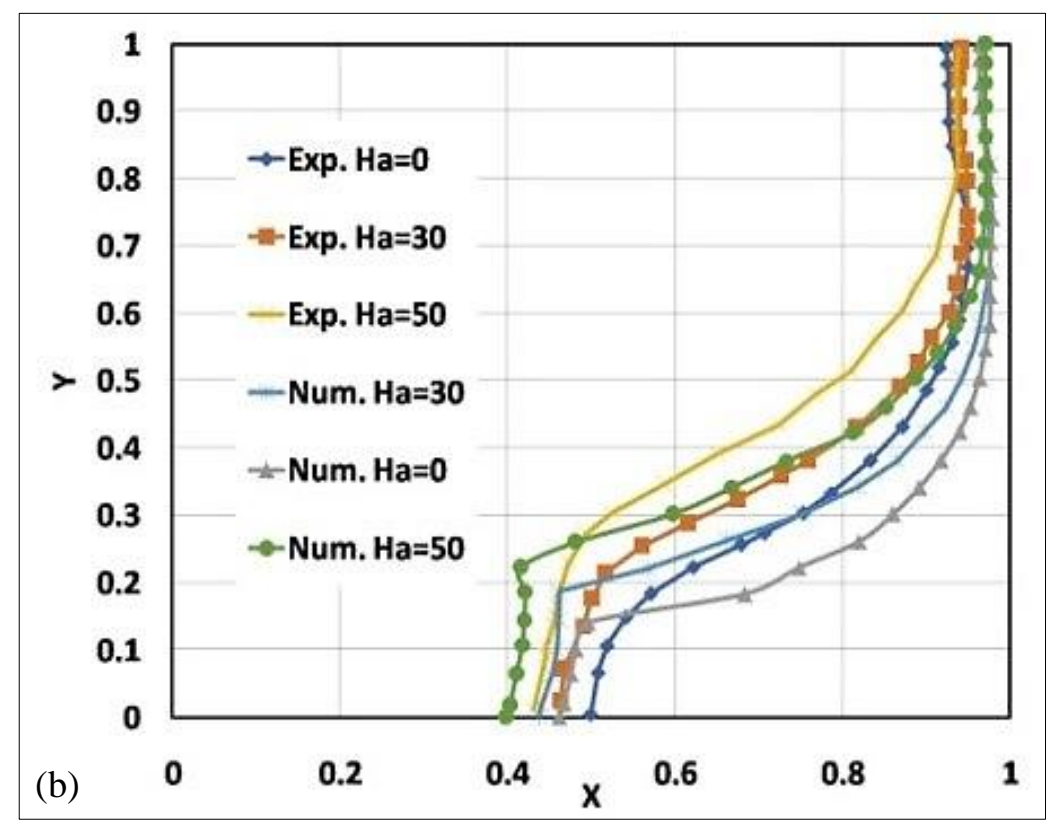

Figure 4. Validation with the data of [21]: (a) $\mathrm{Ha}=\mathbf{0}$ and various $\tau$ 's ( $\mathrm{N}$ indicates numerical data and $\mathrm{P}$ indicates present data); (b) $\mathrm{Ha}=0,30,50$ at $\tau=0.15$ (Exp. indicates experimental data and Num. indicates numerical data).

\section{3-2- Effect of the Rayleigh Number and the Hartmann Number}

To understand the interactions between natural convection and conduction heat transfer in the melt region, under the influence of imposed uniform magnetic field, the effect of $\mathrm{Ra}$ and $\mathrm{Ha}$ in terms of solid-liquid interface, contours of streamlines, temperature and velocity magnitude and average Nusselt number on the hot wall is studied. The results are presented in this and next section.
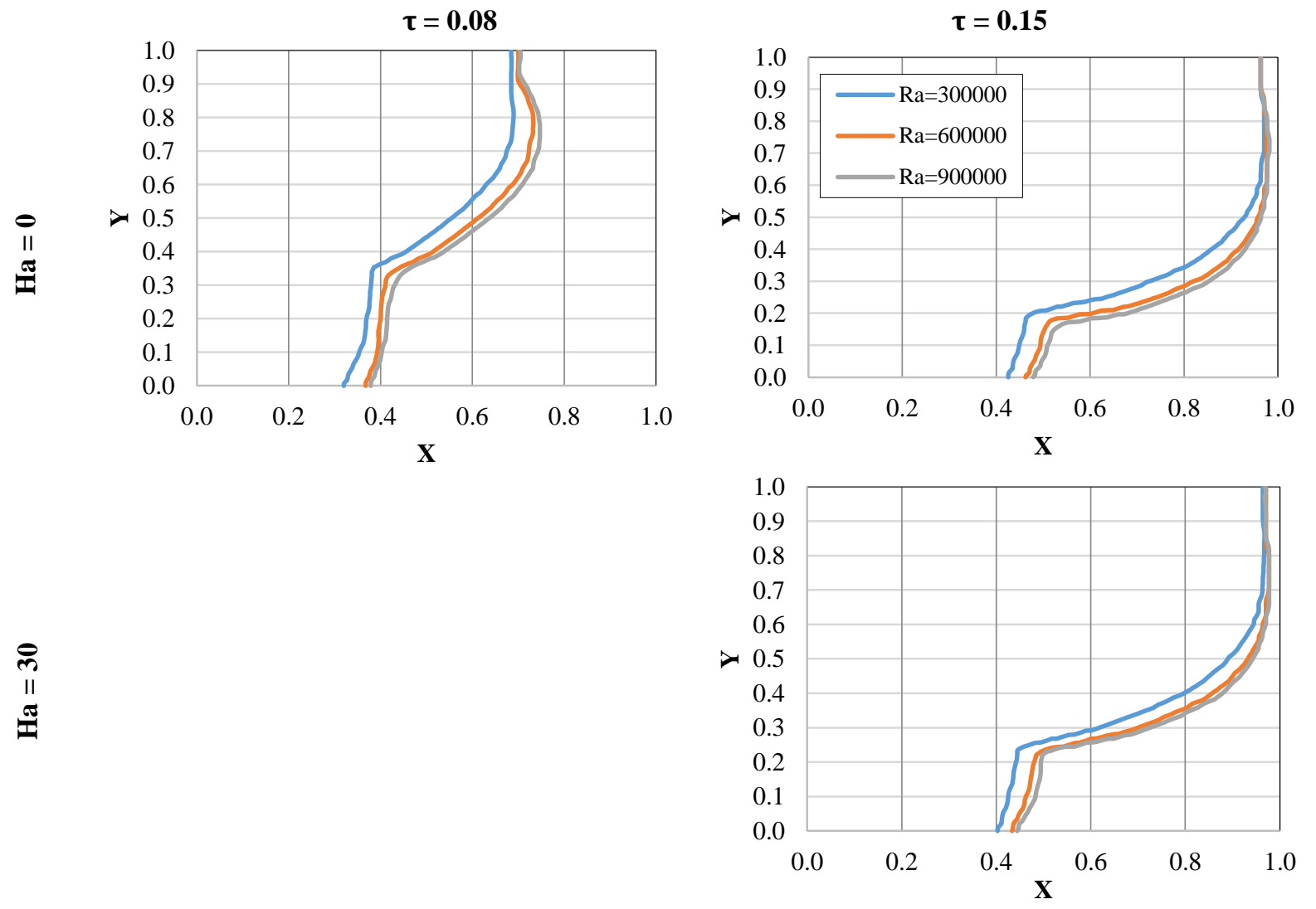

Figure 5. Solid-liquid interface at the various Rayleigh and Hartmann number at dimensionless time, $\tau=0.08$ and 0.15 . 


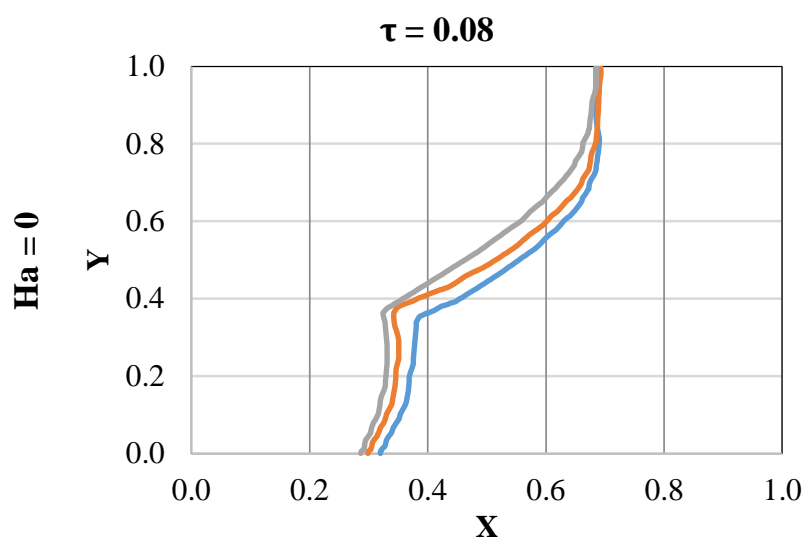

$\tau=0.15$
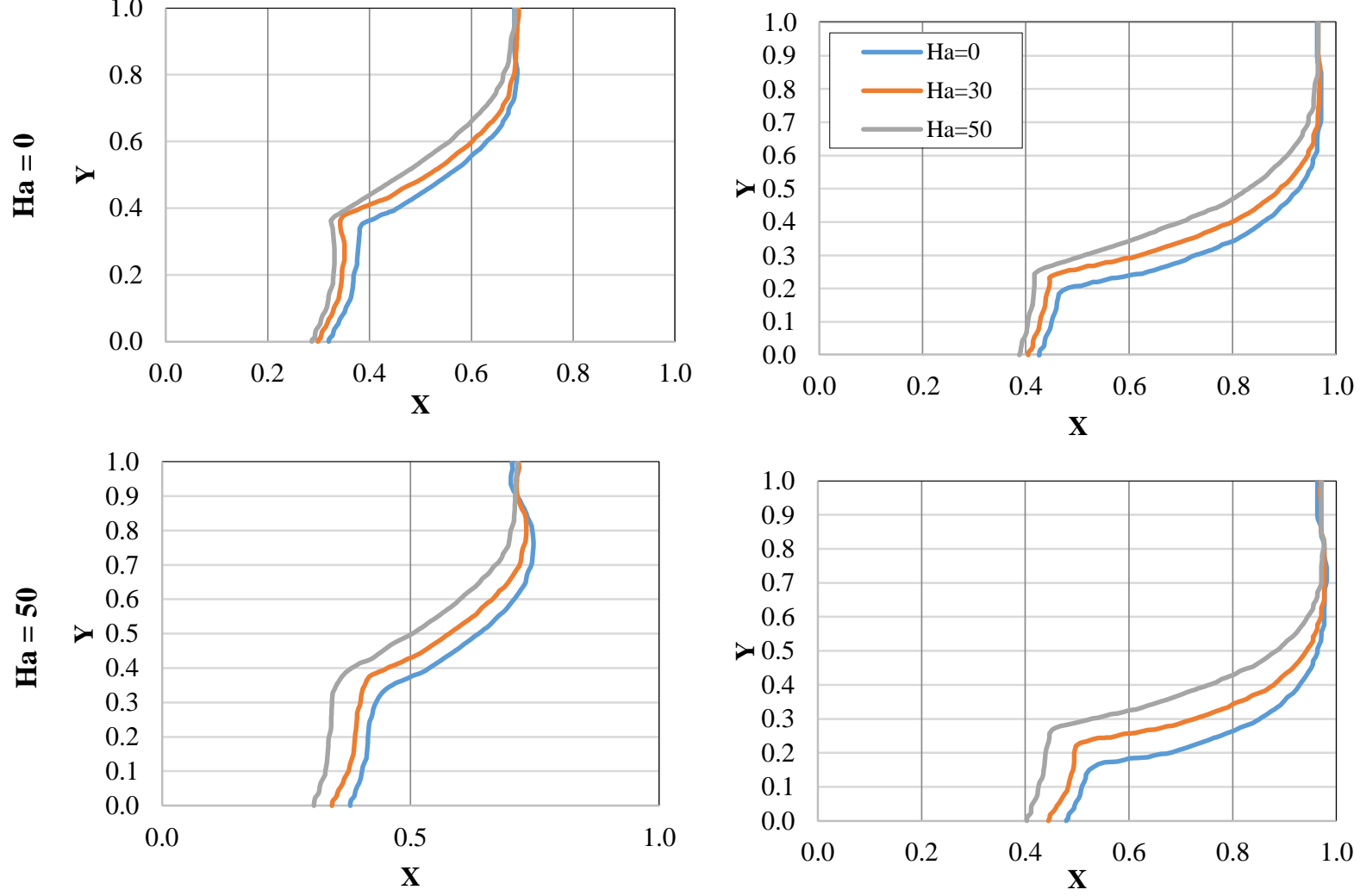

Figure 6. Solid-liquid interface at the various Rayleigh and Hartmann number at dimensionless time, $\tau=0.08$ and 0.15 .

Figures 5 and 6 show the solid-liquid interface at the Rayleigh numbers $\left(\mathrm{Ra}=3 \times 10^{5}, 6 \times 10^{5}\right.$ and $\left.9 \times 10^{5}\right)$ and the Hartmann numbers $(\mathrm{Ha}=0,30$ and 50) at dimensionless time, $\tau=0.08$ and 0.15 . It should be noted that the steady state is reached after $\tau=0.15$. The large Rayleigh number indicates the strength of buoyancy and the higher values of the Hartmann number indicate the strength of the applied electromagnetic force. As can be seen from the figures that the interface progress ahead at higher $\mathrm{Ra}$ as compared to that of lower $\mathrm{Ra}$ at $\mathrm{Ha}=0$ and 30. On the other hand, the interface lags behind at higher $\mathrm{Ha}$ as compared to that of higher $\mathrm{Ha}$ at all $\mathrm{Ra}$. This indicates that the effect of natural convection increases at higher Ra and suppresses at higher Ha.

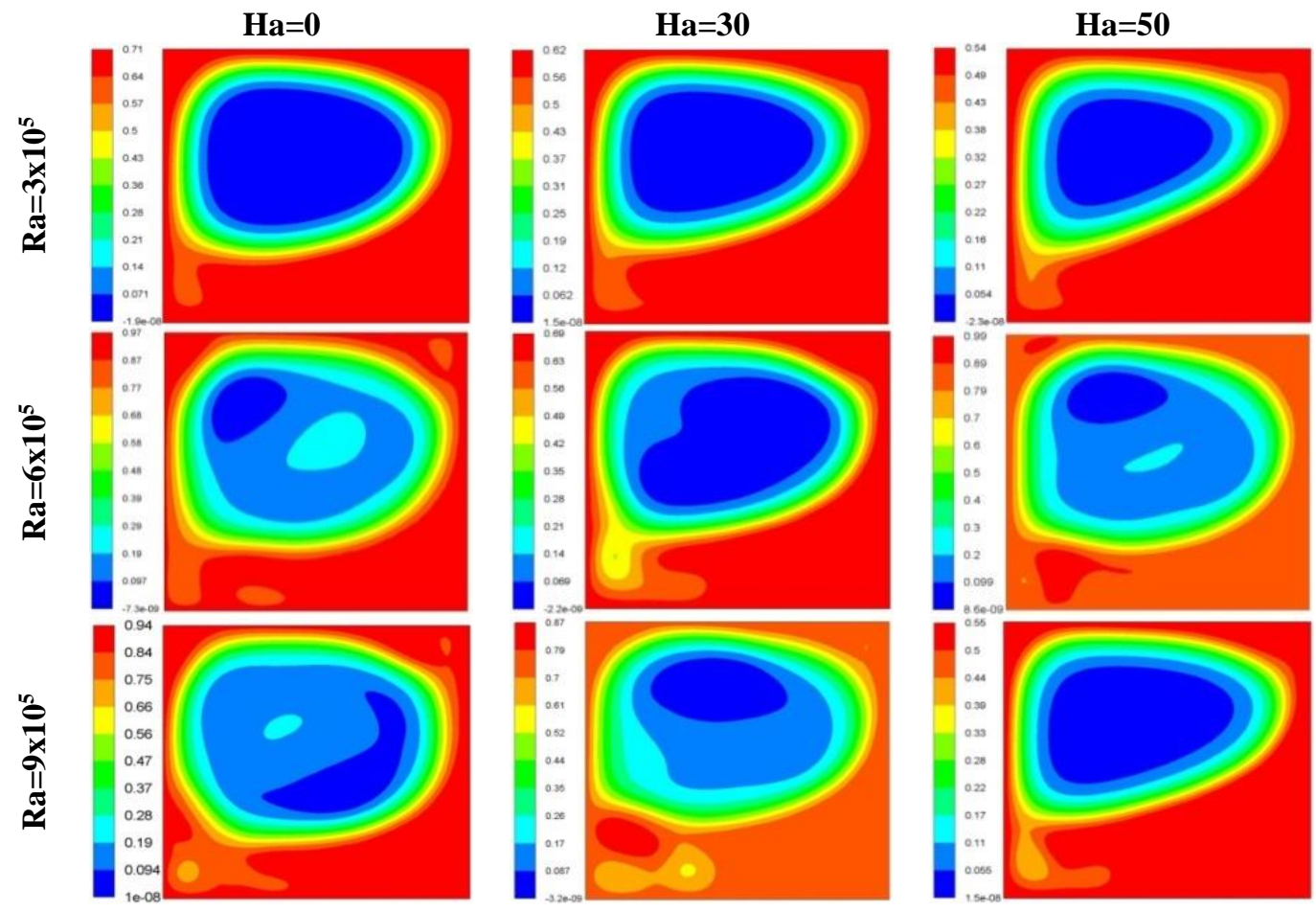

Figure 7. Contours of stream function $\left(\mathrm{m}^{2} / \mathrm{s}\right)$ at steady-state for various Ra and Ha. 

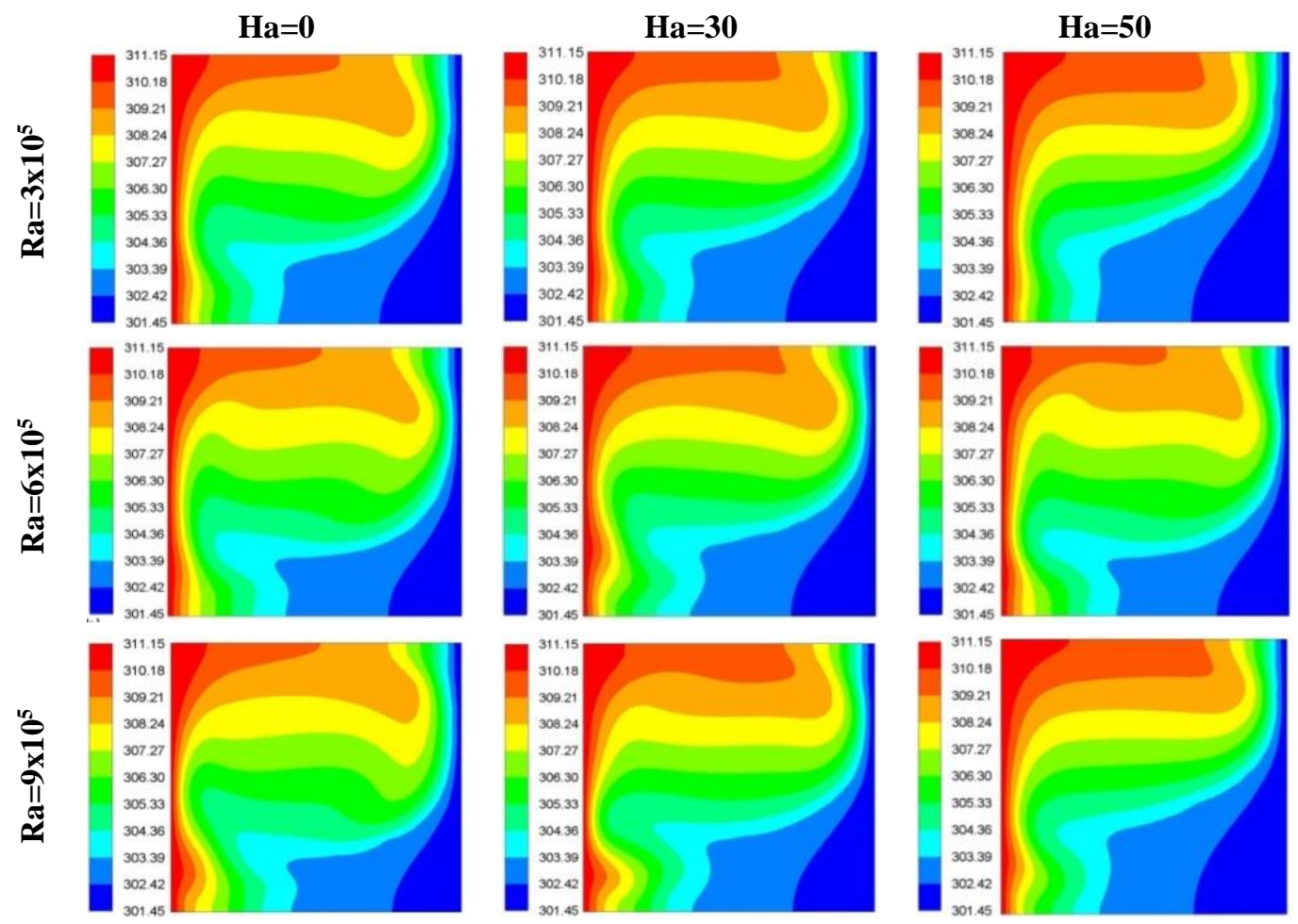

Figure 8. Contours of temperature (K) at steady-state for various Ra and Ha.

Figure 7 shows the streamline contours at steady-state (i.e., $\tau=0.15$ ) for $\mathrm{Ra}=3 \times 10^{5}, 6 \times 10^{5}$, and $9 \times 10^{5}$ and $\mathrm{Ha}=0$, 30 and 50. In the liquid region clockwise rotating vortices are observed as a result of the natural convection that occurred due to the temperature difference between the hot wall and the cooler solid boundary. The liquid near the hot wall rise up and descend near the top insulated wall and the interface and affect the morphology of the interface. Since the top region of the interface always is in contact with the heated molten liquid, as compared to the lower region, the morphology of the interface turns into a convex shape. From Figure 7, it can be observed that the streamlines are much denser at higher Rayleigh numbers. This shows the increase in the strength of the circulation due to natural convection. However, at higher Ha, the denseness of the streamlines decreases and indicates the suppression of natural convection.

Figure 8 shows the temperature contours at steady-state (i.e., $\tau=0.15$ ) for $\mathrm{Ra}=3 \times 10^{5}, 6 \times 10^{5}$, and $9 \times 10^{5}$ and $\mathrm{Ha}=0$, 30 and 50. From Figure 8, it can be observed that the isotherms are curvy at higher Rayleigh numbers. This shows the increase in natural convection. However, at higher Ha, the isotherms are less curvy indicating a departure from heat convection.

Contours of velocity magnitude at $\mathrm{Ra}=6 \times 10^{5}$ and $\mathrm{Ha}=0,30,50$ at $\tau=0.08$, and 0.15 are shown in Figure 9. At fixed $\mathrm{Ra}$, the velocity magnitudes reduce at the steady-state with the increase in Ha. This indicates that increase in the magnetic field suppresses the strength of the circulation and therefore the natural convection.

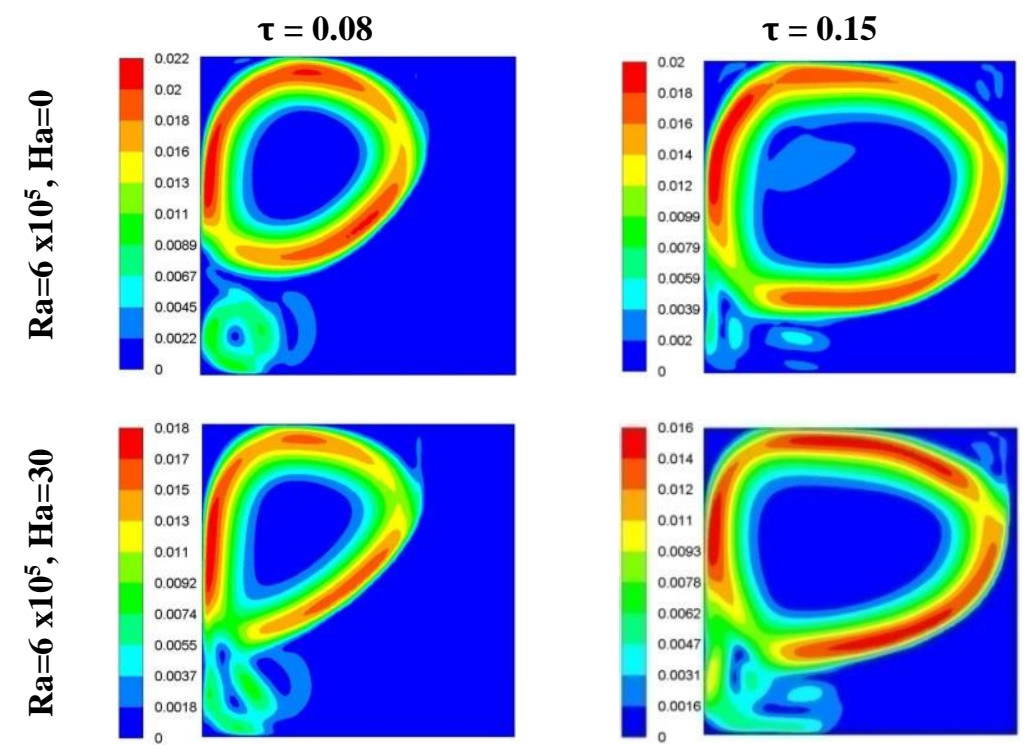



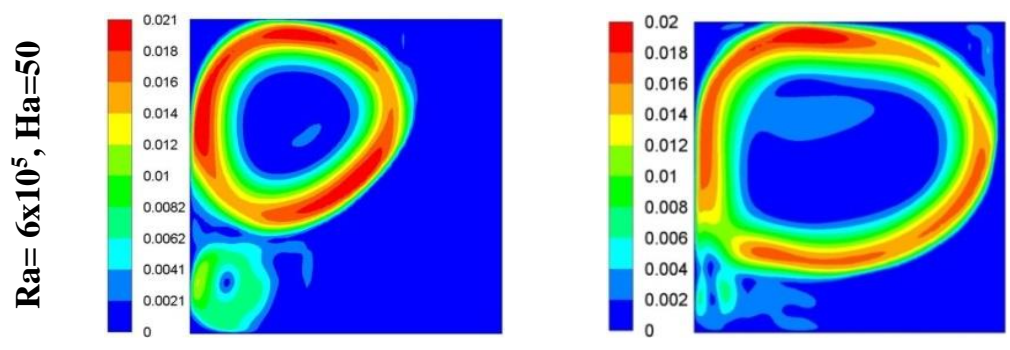

Figure 9. Contours of velocity magnitude $(\mathrm{m} / \mathrm{s})$ at $\mathrm{Ra}=6 \times 10^{5}$ and $\mathrm{Ha}=0,30,50$ at $\tau=0.08$, and 0.15 .

\section{3-3- Averaged Nusselt Number versus Dimensionless Time}

The heat transfer rate at the hot wall is calculated by using the dimensionless averaged Nusselt number $\left((\mathrm{Nu})_{\mathrm{avg}}=\right.$ $\left.\left(\mathrm{q}^{\prime} \cdot \Delta \mathrm{Y}\right) /(\Delta \mathrm{T} \cdot \mathrm{k})\right)$. Figure 10 shows the average Nusselt number on the hot wall as a function of non-dimensional time, $\tau$ for various values of $\mathrm{Ra}$ and Ha. During the initial dimensionless time, the Nusselt number is higher at all Ra. The higher values are due to very thin layer of the melt and sharp temperature gradients near the hot wall. As the melt layer increases, the Nusselt number decreases at the later time due to increase in the thermal resistance. From the figure, it can be noticed that the Nusselt number increases with the increase in Ra due to increase in the local velocities and heat transfer rate. On the other hand, the Nusselt number decreases with the increase in Ha due to suppress in the local velocities and the heat transfer rate.

\section{4- Conclusion}

Two-dimensional unsteady numerical simulations are performed to study an effect of a uniform horizontal magnetic field on melting inside a cavity filled initially with a solid gallium at various Rayleigh numbers $\left(\mathrm{Ra}=3 \times 10^{5}, 6 \times 10^{5}\right.$, and $\left.9 \times 10^{5}\right)$ the Hartmann number $(\mathrm{Ha}=0,30$ and 50) using ANSYS-Fluent with the enthalpy-porosity formulation. A cavity of aspect ratio one is used in the simulation. The horizontal walls of the cavity are considered insulated. The vertical walls are subjected to differential heating. The simulation results are produced in terms of solid-liquid interface, contours of streamlines, temperature and velocity magnitude and average Nusselt number on the hot wall. It is observed that the natural convection increases with the increase in the strength of buoyancy. On the other hand, the natural convection activity decreases with the increase in the strength of the magnetic field. The Average Nusselt number on the hot wall increases with the increase in $\mathrm{Ra}$ and decreases with an increase in Ha. In conclusion the melting rate increases with Ra and decreases with Ha.
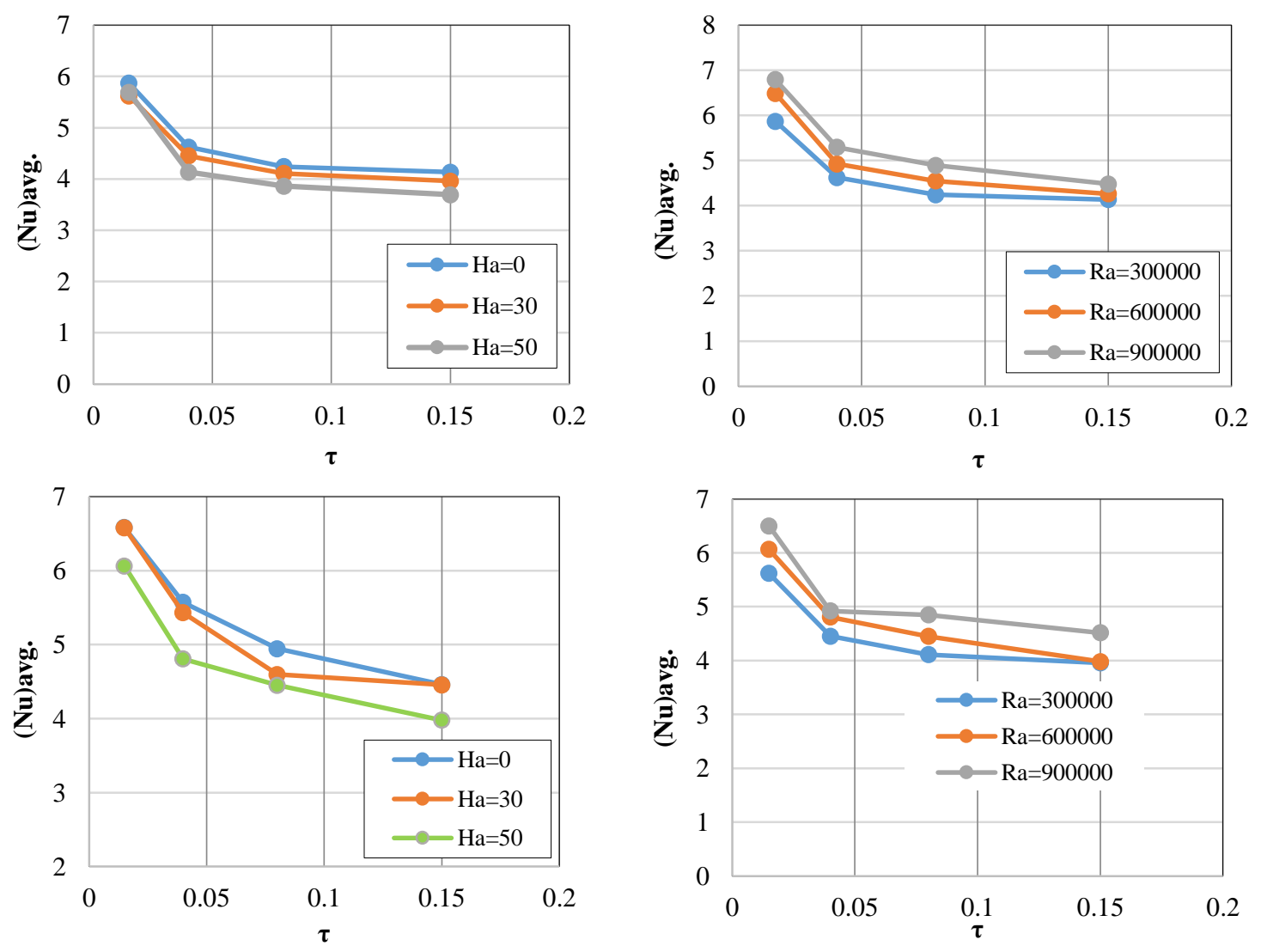

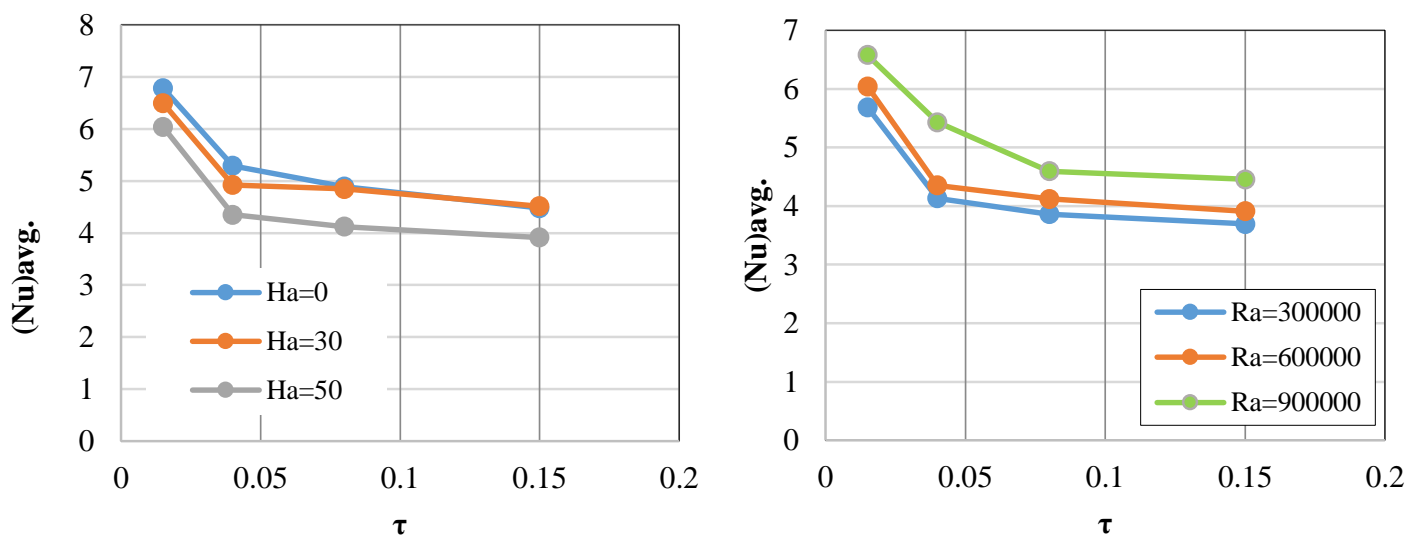

Figure 10. Average Nusselt number versus $\tau$ at various Hartmann numbers and Rayleigh numbers.

\section{5- Conflict of Interest}

The authors declare no conflict of interest.

\section{6- References}

[1] Ostrach, S. "Natural Convection in Enclosures.” Journal of Heat Transfer 110, no. 4b (1988): 1175. doi:10.1115/1.3250619.

[2] Gau, C., and R. Viskanta. "Melting and Solidification of a Pure Metal on a Vertical Wall.” Journal of Heat Transfer 108, no. 1 (1986): 174. doi:10.1115/1.3246884.

[3] Dadzis, K., G. Lukin, D. Meier, P. Bönisch, L. Sylla, and O. Pätzold. "Directional Melting and Solidification of Gallium in a Traveling Magnetic Field as a Model Experiment for Silicon Processes.” Journal of Crystal Growth 445 (July 2016): 90-100. doi:10.1016/j.jcrysgro.2016.03.037.

[4] Brent, A. D., V. R. Voller, and K. J. Reid. "Enthalpy-Porosity Technique for Modeling Convection-Diffusion Phase Change: Application to the Melting of a Pure Metal." Numerical Heat Transfer 13, no. 3 (April 1988): $297-318$. doi:10.1080/10407788808913615.

[5] Bertrand, Olivier, Bruno Binet, Hervé Combeau, Stéphane Couturier, Yves Delannoy, Dominique Gobin, Marcel Lacroix, et al. "Melting Driven by Natural Convection A Comparison Exercise: First Results." International Journal of Thermal Sciences 38, no. 1 (January 1999): 5-26. doi:10.1016/s0035-3159(99)80013-0.

[6] Farsani, Rouhollah Yadollahi, Afrasiab Raisi, Afshin Ahamadi Nadooshan, and Srinivas Vanapalli. "The Effect of a Magnetic Field on the Melting of Gallium in a Rectangular Cavity." Heat Transfer Engineering 40, no. 1-2 (December 22, 2017 ): 53-65. doi:10.1080/01457632.2017.1404821.

[7] Rady, M. A., and A. K. Mohanty. "Natural convection during melting and solidification of pure metals in a cavity." Numerical Heat Transfer, Part A Applications 29, no. 1 (1996): 49-63. doi:10.1080/10407789608913778.

[8] Bucchignani, Edoardo. "An implicit unsteady finite volume formulation for natural convection in a square cavity." Fluid Dyn. Mater. Process 5, no. 1 (2009): 37-60. doi:10.3970/fdmp.2009.005.037.

[9] Joulin, Annabelle, Zohir Younsi, Laurent Zalewski, Daniel R. Rousse, and Stéphane Lassue. "A Numerical Study of the Melting of Phase Change Material Heated from a Vertical Wall of a Rectangular Enclosure.” International Journal of Computational Fluid Dynamics 23, no. 7 (August 2009): 553-566. doi:10.1080/10618560903203723.

[10] Ben-David, O., A. Levy, B. Mikhailovich, M. Avnaim, and A. Azulay. "Impact of Traveling Permanent Magnets on Low Temperature Metal Melting in a Cuboid." International Journal of Heat and Mass Transfer 99 (August 2016): 882-894. doi:10.1016/j.ijheatmasstransfer.2016.04.017.

[11] Kang, Sarah, Kwi-Seok Ha, Hyoung Tae Kim, Ji Hyun Kim, and In Cheol Bang. “An Experimental Study on Natural Convection Heat Transfer of Liquid Gallium in a Rectangular Loop.” International Journal of Heat and Mass Transfer 66 (November 2013): 192-199. doi:10.1016/j.ijheatmasstransfer.2013.07.026.

[12] Bondareva, Nadezhda S., and Mikhail A. Sheremet. "Effect of Inclined Magnetic Field on Natural Convection Melting in a Square Cavity with a Local Heat Source." Journal of Magnetism and Magnetic Materials 419 (December 2016): $476-484$. doi:10.1016/j.jmmm.2016.06.050.

[13] Juel, A., T. Mullin, H. Ben Hadid, and D. Henry. "Magnetohydrodynamic Convection in Molten Gallium.” Journal of Fluid Mechanics 378 (January 10, 1999): 97-118. doi:10.1017/s0022112098003061. 
[14] Xu, B., B.Q. Li, and D.E. Stock. "An Experimental Study of Thermally Induced Convection of Molten Gallium in Magnetic Fields." International Journal of Heat and Mass Transfer 49, no. 13-14 (July 2006): $2009-2019$. doi:10.1016/j.ijheatmasstransfer.2005.11.033.

[15] Sathiyamoorthy, M., and Ali J. Chamkha. "Natural Convection Flow Under Magnetic Field in a Square Cavity for Uniformly (or) Linearly Heated Adjacent Walls.” International Journal of Numerical Methods for Heat \& Fluid Flow 22, no. 5 (June 8 , 2012): 677-698. doi:10.1108/09615531211231307.

[16] Ghalambaz, Mohammad, Ali Doostanidezfuli, Hossein Zargartalebi, and Ali J. Chamkha. "MHD Phase Change Heat Transfer in an Inclined Enclosure: Effect of a Magnetic Field and Cavity Inclination." Numerical Heat Transfer, Part A: Applications 71, no. 1 (January 2, 2017): 91-109. doi:10.1080/10407782.2016.1244397.

[17] Avnaim, M.H., B. Mikhailovich, A. Azulay, and A. Levy. "Numerical and Experimental Study of the Traveling Magnetic Field Effect on the Horizontal Solidification in a Rectangular Cavity Part 1: Liquid Metal Flow Under the TMF Impact." International Journal of Heat and Fluid Flow 69 (February 2018): 23-32. doi:10.1016/j.ijheatfluidflow.2017.11.003.

[18] Avnaim, M.H., B. Mikhailovich, A. Azulay, and A. Levy. "Numerical and Experimental Study of the Traveling Magnetic Field Effect on the Horizontal Solidification in a Rectangular Cavity Part 2: Acting Forces Ratio and Solidification Parameters." International Journal of Heat and Fluid Flow 69 (February 2018): 9-22. doi:10.1016/j.ijheatfluidflow.2017.11.004.

[19] Kaneda, Masayuki, Toshio Tagawa, and Hiroyuki Ozoe. "Natural Convection of Liquid Metal Under a Uniform Magnetic Field with an Electric Current Supplied from Outside.” Experimental Thermal and Fluid Science 30, no. 3 (January 2006): $243-252$. doi:10.1016/j.expthermflusci.2005.07.001.

[20] Zaïdat, Kader, Nathalie Mangelinck-Noël, and René Moreau. "Control of Melt Convection by a Travelling Magnetic Field During the Directional Solidification of Al-Ni Alloys." Comptes Rendus Mécanique 335, no. 5-6 (May 2007): $330-335$. doi:10.1016/j.crme.2007.05.010.

[21] Doostani, Ali, Mohammad Ghalambaz, and Ali J. Chamkha. "MHD Natural Convection Phase-Change Heat Transfer in a Cavity: Analysis of the Magnetic Field Effect.” Journal of the Brazilian Society of Mechanical Sciences and Engineering 39, no. 7 (February 8, 2017): 2831-2846. doi:10.1007/s40430-017-0722-z. 